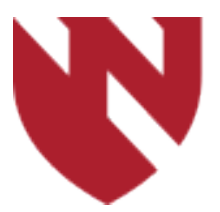

December 2019

\title{
A Case of Monocytic Pleocytosis in West Nile Neuroinvasive Disease
}

\author{
Brian Villafuerte Trisolini \\ University of Nebraska Medical Center \\ Mohamed Taha \\ University of Nebraska Medical Center \\ Maryam Matloub \\ University of Nebraska Medical Center \\ Thomas Diesing \\ University of Nebraska Medical Center
}

Tell us how you used this information in this short survey.

Follow this and additional works at: https://digitalcommons.unmc.edu/gmerj

Part of the Higher Education Commons, and the Medicine and Health Sciences Commons

\section{Recommended Citation}

Villafuerte Trisolini, B., Taha, M., Matloub, M., , Diesing, T. A Case of Monocytic Pleocytosis in West Nile Neuroinvasive Disease. Graduate Medical Education Research Journal. 2019 Dec 13; 1(1).

https://digitalcommons.unmc.edu/gmerj/vol1/iss1/34

This Conference Proceeding is brought to you for free and open access by DigitalCommons@UNMC. It has been accepted for inclusion in Graduate Medical Education Research Journal by an authorized editor of DigitalCommons@UNMC.For more information, please contact digitalcommons@unmc.edu. 


\section{A Case of Monocytic Pleocytosis in West Nile Neuroinvasive Disease}

Creative Commons License

(c) (i) (9)

This work is licensed under a Creative Commons Attribution-Noncommercial-No Derivative Works 4.0 License. 


\section{Risk of Sleep Disorders in Hospitalized Patients with Obstructive Lung Disease: An Observational Study Nancy H Stewart, Ryan Walters, Babak Mokhlesi, Diane Lauderdale, Vineet M Arora}

\section{Mentor: Vineet M Arora}

Program: Sleep Medicine

Background \& Objectives: Obstructive lung disease (OLD) includes chronic obstructive lung disease (COPD) and asthma, and affects over 24 million adults in the US. OLD is the 3rd leading cause of morbidity and mortality in US, and a significant cost to US healthcare system. 1 in 4 adults have Obstructive Sleep Apnea (OSA), and 90\% are undiagnosed. Patients with untreated COPD/OSA overlap have high risk of re-hospitalization and death. No study yet characterizes risk of undiagnosed sleep disordered breathing in hospitalized patients with obstructive lung disease.

Methods: During a prospective cohort study of medical inpatients, participants were interviewed regarding sleep prior to admission and inpatient daily sleep. Sleep efficiency and duration were measured with actigraphy. Within participating subjects, 3 groups were defined: subjects with a primary diagnosis of COPD, subjects with COPD as a secondary diagnosis, or those without history of a COPD diagnosis.

Results: OLD patients have 2.5-times higher odds of insomnia. Patients with COPD, have a greater risk of OSA, compared to those without COPD (64.7\% vs. $37.9 \%, \mathrm{p}=.002)$. On average, patients with COPD received 40 minutes less sleep than those without COPD (median sleep duration 284.5 minutes (IQR 162.5- 389.5) vs. 324.0 minutes (IQR 232.5-413.5). The median sleep efficiency for patients with COPD was $67.4 \%$ (IQR 43.082.8 ) vs. $75.9 \%$ (IQR 61.6- 85.8) for patients without a COPD diagnosis.

Conclusions: Patients with obstructive lung disease have high odds of insomnia, worse inhospital sleep quality and quantity.

https://doi.org/10.32873/unmc.dc.gmerj.1.1.033

\section{A Case of Monocytic Pleocytosis in West Nile Neuroinvasive Disease Brian Villafuerte Trisolini, Mohamed Taha, Maryam Matloub, Thomas Diesing}

Mentor: Thomas Diesing

Program: Neurology

Background \& Objectives: The most commonly reported cerebrospinal fluid (CSF) cell counts in West Nile (WN) encephalitis is early neutrophilic pleocytosis followed by lymphocytic pleocytosis. We aimed to describe an atypical CSF cell count in a patient with West Nile acute encephalitis and flaccid quadraparesis.

Methods: We retrospectively review history of present illness, past medical history, admission course, laboratory and imaging results of one patient.

Results: A middle-aged patient with a past medical history of controlled hypothyroidism presented to the emergency department for acute and progressive fever and confusion. Neurological exam was remarkable for lethargy, flaccid quadraparesis and was intubated for management of airway and hypercapnic respiratory failure. Magnetic resonance imaging of complete spine showed contrast enhancement of lower thoracic and lumbar ventral roots. Nerve conduction studies showed an active motor neuronopathy. CSF showed 98 white blood cells with 62 $\%$ monocytes, $25 \%$ lymphocytes, $13 \%$ polymorphonuclear; and protein $128 \mathrm{mg} / \mathrm{dL}$. Pathology review showed monocytes, small lymphocytes and occasional neutrophils. Infectious etiologies (Gram stain, aerobic and fungal cultures, cryptococcal antigen, herpes simplex virus, varicella-zoster virus, cytomegalovirus, enterovirus, syphilis, HIV and tuberculosis) returned negative. The patient was started on plasma exchange, but was discontinued due to a positive result for $\mathrm{WN}$ virus specific IgM and negative for IgG. With supportive treatment, the patient regained consciousness and strength mildly improved, however a tracheostomy and a percutaneous endoscopic gastrostomy tube were warranted.

Conclusions: We suggest consideration of neuroinvasive West Nile Virus despite a monocytic pleocytosis in the setting of encephalitis with flaccid paralysis

https://doi.org/10.32873/unmc.dc.gmerj.1.1.034

\section{University of Nebraska Medical Center Pressure Ulcer Prevention Initiative}

Stephan Barrientos, Maria Tecos, Kaeli Samson, Lynette Smith, Chandrakanth Are, Perry Johnson, Jason Miller, Debra Reilly

Mentor: Debra Reilly

Program: Plastic and Reconstructive Surgery

Background \& Objectives: Pressure ulcers (PUs) are a major health care burden, resulting in increased morbidity, mortality and cost. The Committee of Medicare and Medicaid Services (CMS) has mandated that advanced stage PU's acquired after hospital admission are "reasonably preventable events" and costs related to ulcer management are not reimbursable. The primary objective of this study was to determine the rate of hospital acquired pressure ulcers (HAPUs) at the University of Nebraska Medical Center (UNMC). A secondary objective was to measure nursing compliance with hospital approved PU prevention protocols.

Methods: This study was a single site observational retrospective chart review from
January 2015 - October 2017. Inclusion criteria included: any gender, any ethnicity, any comorbidity, age $>19$ and documented HAPU development stage II or greater. Data analysis allowed for quarterly HAPU rates. This data was stratified based on PU location, unit, and comorbidity. Nursing compliance was measured in two ways. First, by identifying whether a skin assessment (Braden Score) was performed each day from admission to the initial identification of the PU and second, by identifying trends in Braden Scores prior to PU development.

Results: The incidence of UNMC HAPUs per quarter ranged from (2.18-4.46\%). Eleven of the 12 quarters had higher rates than the national average (2.5\%). Nursing staff performed a Braden assessment the majority of the time during a patient's hospitalization.
There are multiple instances where the Braden Score worsened prior to PU identification. There were multiple instances when a PU was identified at the quarterly wound healing assessment.

Conclusion: UNMC has a consistently higher rate of HAPU than the national average. The nursing staff appears to be performing a skin assessment on most patients. There are instances where PUs were not identified by the nursing staff. There are instances where the Braden Score was worsening prior to PU development. Institution wide in-service may be needed to improve pressure ulcer prevention at UNMC.

https://doi.org/10.32873/unmc.dc.gmerj.1.1.035 